\title{
A mídia espontânea no entretenimento: Um estudo de caso da série The Umbrella
}

\author{
Academy \\ Spontaneous media in entertainment: A case study from The Umbrella Academy \\ series

\begin{abstract}
Josi Nicoski Flores Graduanda. Faculdade SATC (FASATC) - Brasil. josi.nicoski@gmail.com.
Diego Piovesan Medeiros Doutor em Design. Faculdade SATC (FASATC) - Brasil. diego.medeiros@satc.edu.br.
\end{abstract}

\section{RESUMO}

Este trabalho procura identificar como a mídia espontânea gerada pelos fãs de um produto de entretenimento pode gerar amplitude para o mesmo, utilizando a série The Umbrella Academy como estudo de caso. No referencial teórico foram utilizados estudos sobre os tipos de mídia, o entretenimento, a definição dos pontos de contato e como aparecem no entretenimento, além do comportamento do consumidor, abrangendo o consumidor como fã, com autores como Kotler (2000), Wheeler (2012) e Jenkins (2009). A análise busca identificar diferentes tipos de mídia espontânea, levantando publicações e ações geradas pelo público da série na internet, em diferentes mídias sociais, relacionando-as como pontos de contato da série. Assim, o resultado da análise que é composta pelo levantamento de mídia proprietária e paga utilizada pela Netflix para a divulgação da série, assim como a mídia espontânea gerada pelos fãs, reforçam a relação dos pontos de contato ao produto de entretenimento, ampliando seu universo de divulgação.

Palavras-chave: Entretenimento. Pontos de contato. Mídia espontânea.

\section{ABSTRACT}

This work seeks to identify how spontaneous media generated by fans of an entertainment product can give it amplitude, using The Umbrella Academy series as a case study. As theoretical reference we used studies on the types of media, entertainment, the definition of touchpoints and how they appear in entertainment, as well as consumer behavior, covering the consumer as a fan, according to authors such as Kotler (2000), Wheeler (2012) and Jenkins (2009). The analysis seeks to identify different types of spontaneous media, publications and actions generated by the audience of the series on the Internet, in different social media, relating them as touchpoints of the series. The result of the analysis that is composed of the survey of proprietary and paid media used by Netflix for the dissemination of the series, and also the spontaneous media generated by fans, reinforces the relationship of touchpoints to the entertainment product, expanding the reach of its dissemination.

Keywords: Entertainment. Touchpoints. Spontaneous media. 


\section{INTRODUÇÃO}

Baseado em histórias reais ou ficcionais, com heróis, vilões e princesas, o mercado cinematográfico deixou de existir apenas nas telas de cinema nos últimos anos, ganhando espaço e gerando acessibilidade por meio da internet, com as plataformas de streaming como um dos meios propagadores da indústria do entretenimento.

Em uma sociedade conectada às redes wireless, o entretenimento então passa a ser um elemento do consumo, onde, segundo Pereira (2013), as empresas e marcas se deram conta de que não basta apenas oferecer um produto ou serviço de qualidade, mas, além disso, é preciso gerar experiências aos consumidores nutridos pela cultura de massa.

Para as marcas de entretenimento, as experiências que reforçam os pontos de contato com seus consumidores são capazes de gerar um público engajado, que compartilha e produz conteúdo por conta própria, expandindo o universo criado pela marca. Desta maneira, a partir desse pressuposto, este trabalho procura responder a seguinte pergunta: Como a mídia espontânea pode gerar amplitude para um produto de entretenimento?

Como objetivo de pesquisa, esse trabalho busca identificar diferentes formas de publicação e divulgação espontâneas geradas pelo público consumidor de entretenimento, sendo que o objeto de pesquisa escolhido é a série The Umbrella Academy, lançada em 15 de fevereiro de 2019 pela plataforma de streaming e entretenimento Netflix.

Além de identificar a mídia espontânea gerada pelo público, esse estudo procura em seus objetivos específicos relacionar os pontos de contato em marcas de entretenimento, identificar o comportamento do consumidor que os leva a serem propagadores de uma marca e ainda, analisar o caso da série The Umbrella Academy por meio dos conceitos apresentados.

A pesquisa justifica-se ao apresentar os conceitos de pontos de contato e a mídia espontânea na fundamentação do tema, relacionando-os a uma marca de entretenimento com base no interesse pessoal da autora.

Do ponto de vista acadêmico, esse trabalho procura entender como a relação com o consumidor, por meio da geração de mídia espontânea, pode gerar amplitude para um produto de entretenimento, servindo como exemplo para os estudos nas áreas de comportamento do consumidor e entretenimento e conteúdo.

Enquanto, mercadologicamente, a pesquisa justifica-se mostrando a importância do fortalecimento dos pontos de contato de marca para uma possível geração de mídia espontânea, podendo ser um conceito aplicado não somente às marcas de entretenimento.

Este é um estudo de natureza básica, segundo Rauen (2015), pois não possui aplicação prática. Com abordagem qualitativa, ao dar preferência para dados descritivos, trata-se de uma pesquisa bibliográfica exploratória, pois utiliza livros, artigos científicos e materiais gráficos em sua fundamentação. A análise deste trabalho trata-se de um estudo de caso da série The Umbrella Academy, de 2019. Os procedimentos de análise serão apresentados na seção 4.1, do capítulo referente ao estudo de caso, após a apresentação dos conceitos necessários para este trabalho.

\section{MÍDIA E ENTRETENIMENTO}

A fim de identificar a mídia espontânea gerada pelo público, como sendo um dos objetivos deste artigo, é preciso compreender o significado da mídia em si. Desta forma, esta seção busca entender o significado do termo e relacionar aos tipos existentes.

\subsection{Tipos de mídia}

O consumo de mídia faz parte dos hábitos da sociedade, uma vez que dá voz ao diálogo entre marcas e consumidores. Para Kotler, Kartajaya e Setiawan (2017), quando uma empresa define o que vai oferecer ao 
consumidor, ela precisa entender como irá fazê-lo, informando ao público as características e vantagens de seu produto/serviço. Dentro dessa perspectiva, entra o conceito dos canais de comunicação, que atuam como os propagadores dessas informações.

Segundo Kotler (2000), a mídia faz parte dos canais de comunicação não pessoais, sendo constituída pela comunicação escrita (jornais, revistas, mala direta), transmitida (rádio, televisão), eletrônica (internet) e expositiva (outdoors, cartazes). Desta maneira, como um canal de comunicação, a mídia serve como a expositora de uma mensagem, elaborada com um objetivo definido pela marca, capaz de persuadir o espectador a agir da forma esperada.

Para autores como Chinem (2017), o termo "mídia" significa qualquer meio de comunicação de massa, podendo ser dividida entre a mídia escrita, que é constituída por jornais, panfletos e outdoors, e a mídia eletrônica, que engloba meios como a televisão, rádio e internet.

A fim de compreender as diferentes mídias como canais de comunicação e as experiências que geram, é preciso entender que, de acordo com a afirmação de Silverstone (1999), os espaços de engajamento e experiência de mídia são tanto reais como simbólicos. Para o autor, são "as rotinas que definem os lugares do, e para o, consumo da mídia" (SILVERSTONE, 1999, p. 161). Desta forma, assim como as mídias são consumidas de maneiras distintas, elas também se apresentam de múltiplas formas.

A comunicação de marcas inicia-se pelos meios em que as mesmas podem controlar. Esses, que são canais de comunicação pessoais e não pessoais (KOTLER; ARMSTRONG, 2007), são caracterizados principalmente por carregarem o propósito da empresa em suas mensagens, utilizando os veículos e mídias em que a empresa pode controlar.

Desta forma, um exemplo dessa mídia proprietária é o site institucional de uma marca, como no exemplo da figura 1.

Figura 1 - Site Institucional

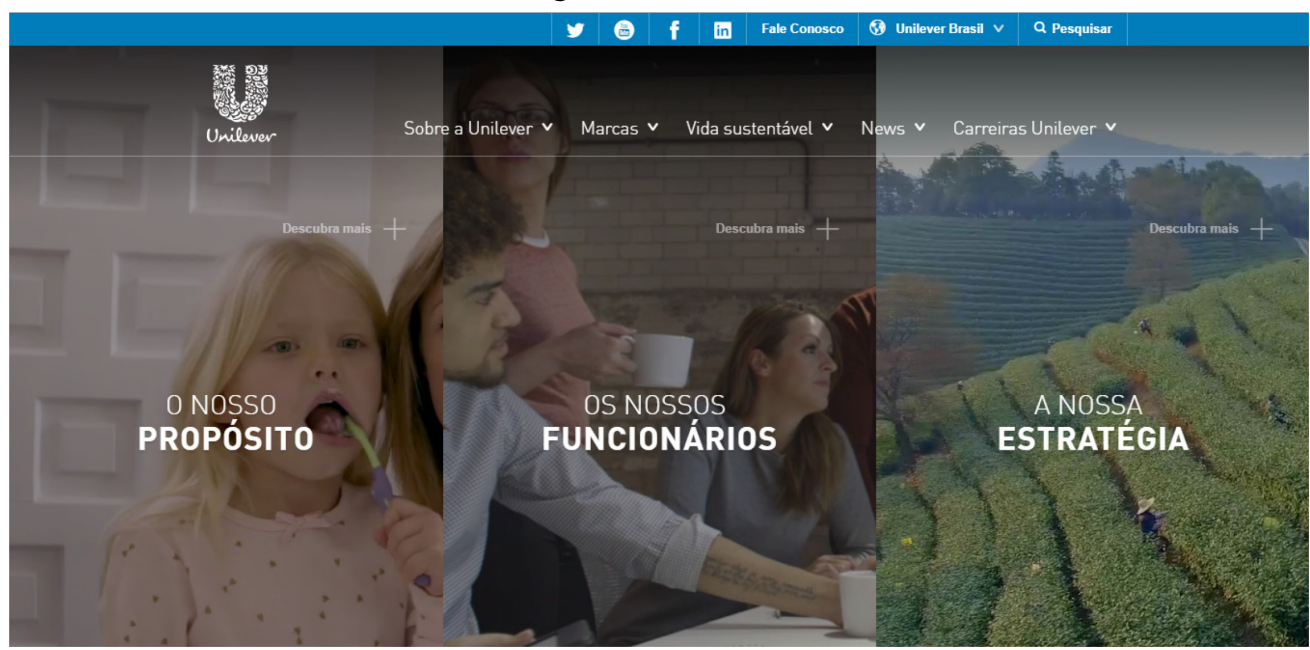

Fonte: UNILEVER (2019)

Quando busca representar uma marca, o profissional de mídia deve escolher a maneira mais precisa para que seu público-alvo seja atingido e possa compreender a mensagem (KOTLER; ARMSTRONG, 2007). Esse processo, que implica na escolha de veículos de comunicação adequados para o anunciante, diz respeito à Mídia Paga, que remete à história da propaganda.

Enquanto, na Antiguidade clássica, os romanos utilizavam paredes para anunciar lutas de gladiadores, na era moderna, o investimento em propaganda realizado por empresas comerciais e institucionais gira a roda da economia (KOTLER; ARMSTRONG, 2007). Um breve exemplo disso encontra-se na 19० Pesquisa Global de Entretenimento e Mídia, realizada pela PricewaterhouseCoopers Brasil (2018), que estima que 718 bilhões de dólares serão gastos globalmente em Publicidade até 2022.

Por meio de veículos de massa, como a televisão, um anúncio pode atingir um número alto de consumidores a um custo relativamente baixo por exposição, fazendo com que a marca possa repetir a 
mensagem diversas vezes e estabelecer um lugar de respeito aos olhos do público, uma vez que a natureza pública da propaganda permite um olhar mais verdadeiro ao que foi anunciado (KOTLER; ARMSTRONG, 2007).

Enquanto, segundo afirmam Kotler e Armstrong (2007), a propaganda de massa também pode ser deficiente por não possuir um nível pessoal, a mídia no meio digital possibilita um discurso pessoal e segmentado para atrair novos consumidores. Para Blume (2009, p. 126), “É preciso ter sempre presente que a internet é uma mídia extremamente segmentada. Quem souber usar esta característica a seu favor, pode ter muito sucesso."

Essa opção torna o trabalho das empresas assertivo, pois destinam sua verba a um público específico, obtendo resultados detalhados. Esses dados, que se tornaram os responsáveis pela confiança dos investimentos em propaganda na internet, são chamados de métricas. Para Veronezzi (2009), a informática possibilitou a criação dessas métricas, que são ferramentas que levantam os dados necessários para medir os acessos às páginas da internet.

Graças à tecnologia da internet, é possível acompanhar cada clique do público, obtendo dados exatos da performance de anúncios, em tempo real, garantindo uma flexibilidade antes nunca alcançada em outras mídias (BLUME, 2009, p. 127).

Além disso, com a popularização e democratização da internet, Ferrari (2015) afirma que a possibilidade de criação de comunidades segmentadas por interesses é um dos elementos que está transformando a comunicação na sociedade, abrindo um novo espaço para possibilidades dentro da Internet. As mídias sociais possibilitam um espaço de cooperação e compartilhamento de experiências, segundo Ferrari (2015, p. 118), "a sociedade atual move-se em torno das pessoas, das suas histórias, de seus costumes, suas experiências de vida, enfim da informação individualizada e da tão falada democracia digital".

Desta maneira, as mídias sociais, espaços criados na web para a comunidade, se difundem como um espaço utilizado para comunicação onde as pessoas podem ser atingidas pelas marcas, mas acima disso, geram conteúdo e mídia espontânea, em que cada voz é ouvida e amplificada pelos compartilhamentos.

A mídia espontânea, definida por Kotler (2000) como "boca a boca", faz parte dos canais de comunicação pessoais, nos quais a comunicação é feita em forma de diálogo. Segundo o autor, "As fontes de boca a boca são convincentes: o boca-a-boca é o único método de promoção de consumidores, feito por consumidores e para consumidores." (KOTLER, 2000, p. 580).

Portanto, pode-se assumir que a mídia espontânea é uma mídia que não é paga e tampouco produzida pela marca. Ela parte do consumidor que, contente ou descontente com um produto ou serviço, utiliza os seus meios de comunicação para propagar sua opinião.

Essa afirmação pode ser confirmada por Xavier (2015), pois, para o mesmo, com a popularização das mídias e dos veículos de comunicação, juntamente com a globalização e a chegada da internet, interações que antes pareciam impossíveis, por conta de diferenças culturais, políticas e geográficas, por exemplo, tornaramse facilmente alcançáveis, tanto no âmbito pessoal como para com as marcas. Desta forma, Xavier (2015) afirma que se iniciou um boca a boca planetário, em que todas as pessoas podem emitir opiniões independentemente se dominam ou não um assunto, e isso, é claro, inclui pessoas e marcas.

É possível compreender, por meio da figura abaixo, que a mídia engloba os três conceitos apresentados, sendo a mídia paga, mídia proprietária e mídia espontânea. Observa-se que nenhum desses termos é maior que o outro, e que suas convergências no gráfico formam a mídia. 
Figura 2 - Os três tipos de mídia

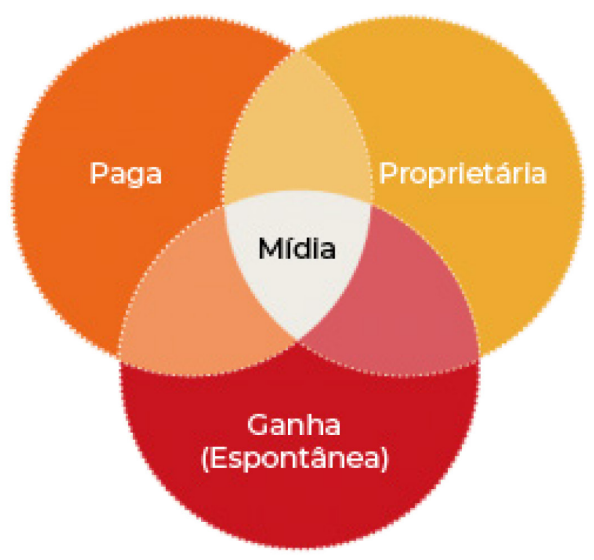

Fonte: Thiel (2019).

A importância da mídia é afirmada por Silverstone (1999, p. 12), quando o mesmo diz que "passamos a depender da mídia, tanto impressa como eletrônica, para fins de entretenimento e informação". O autor declara que a mídia é parte da experiência (SILVERSTONE, 1999), enquanto para Jenkins (2009, p. 55), esse compartilhamento encontra-se tanto no ambiente pessoal quanto digital: "Para quase todos nós, a televisão fornece material para a chamada conversa na hora do cafezinho. E, para um número crescente de pessoas, a hora do cafezinho tornou-se digital". Desta maneira, pode-se perceber na fala dos autores que a mídia supera o seu papel de transmitir uma mensagem para as marcas, tornando-se também um produto de entretenimento pensado para o público.

A palavra entretenimento provém de "entreter", que significa divertimento, o que distrai e serve como passatempo (DICIO, 2019). Desta maneira, o entretenimento é o principal produto da cultura da mídia para Rocha e Castro (2009), utilizando meios para seduzir a audiência para que ela se identifique com as representações abordadas. Segundo as autoras, o entretenimento está estritamente ligado à Sociedade do Espetáculo, termo utilizado na década de 1960 por Guy Debord, como uma análise da sociedade moderna.

Segundo Rocha e Castro (2009, p. 50), "[...] a noção de espetáculo aparece como uma forma alienante de manipulação ideológica e econômica que nutre uma cultura de lazer e entretenimento fácil, visando à docilização das audiências". Desta forma, a "docilização" é a forma utilizada para fazer com que as pessoas, que já buscam por entretenimento, entender e fazer parte de discursos. Xavier (2015, p. 49), pode confirmar essa afirmação quando reforça a importância do entretenimento:

Buscamos entretenimento, não apenas por hedonismo, mas também por necessidade de oxigenação espiritual, pertença grupal, socialização, atualização, informação, enfrentamento de nossos medos, segurança emocional, autoconfiança, exploração de nosso imaginário, reafirmação de nossos princípios éticos e morais. (XAVIER, 2015, p. 49).

De acordo com Pereira (2013), as esferas da sociedade utilizam o entretenimento como maneira para construir os seus discursos. Pode-se assumir que o entretenimento permite com que marcas comuniquem suas mensagens de uma maneira próxima ao público, que consome diariamente o entretenimento por meio das mídias. Desta maneira, partindo do pressuposto que o entretenimento se apresenta de diferentes maneiras na mídia, é possível analisar as principais plataformas de entretenimento e seus pontos de contato na mídia.

\subsection{Pontos de contato no entretenimento}

Dentro do desenvolvimento de marcas, Wheeler $(2012$, p. 13) trata os pontos de contato como o "[...] uma oportunidade para aumentar a consciência de marca e promover a fidelidade do cliente". Os pontos de 
contato serão os responsáveis por definir a maneira como a marca é percebida, criando e estreitando a relação com o público.

Por meio da figura abaixo, é possível compreender a relação estabelecida pelo ponto de contato, que se torna a ligação entre a empresa que possui a solução para a necessidade específica de uma pessoa.

Figura 3 - Definição de pontos de contato

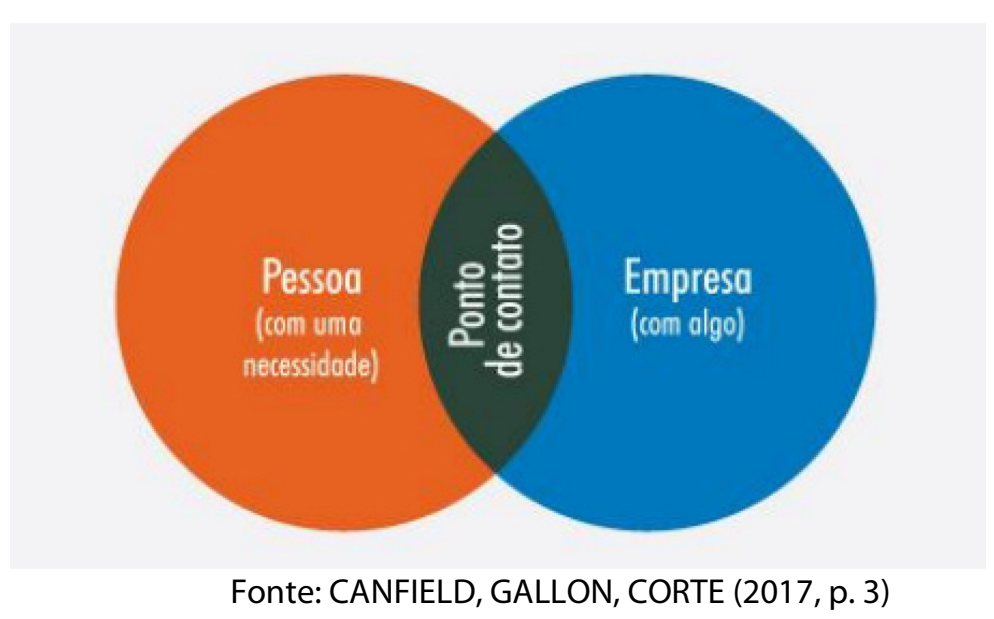

Essa ligação pode ser estabelecida com um objeto utilizado pela marca. Wheeler (2012) define que cartões de visita, papéis timbrados, mala-direta, embalagens, websites e até a propaganda são pontos de contato de marca, para citar alguns exemplos. Desta maneira, cada representação da marca, seja de uma campanha publicitária até o tom de voz de um atendente no telefone comercial da empresa, passa a se tornar uma chance de comunicar os propósitos definidos ao público.

Para Gaspary (2013, p. 25):

Quando esses pontos estão espalhados por diferentes tipos de canais, mídias e plataformas, as oportunidades para a construção de impressões memoráveis aumentam, gerando mais oportunidades para o cliente se identificar com a marca e querer ser fiel a ela.

Essa afirmação pode ser confirmada por Wheeler (2012) que, na figura abaixo, categoriza diferentes pontos de contato, partindo do princípio que eles são guiados pela marca, que se encontra no centro do esquema. 
Figura 4 - Pontos de contato de marca

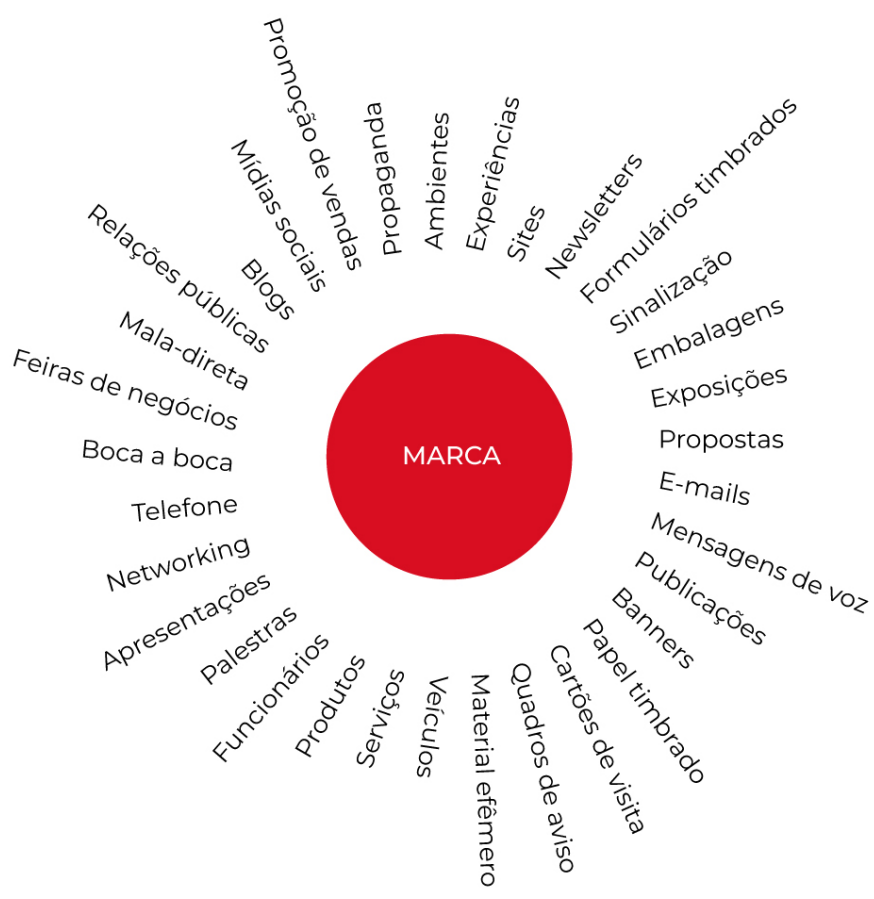

Fonte: WHEELER, 2012, p. 13. Adaptado pela autora.

Os pontos de contato abordados por Wheeler (2012) reforçam conexões entre marcas e seus consumidores. Se o Entretenimento for observado como centro, seus pontos de contato possuem relação com toda conexão que a narrativa aborda juntoa sua audiência.

Aplicando assim, o conceito de pontos de contato no entretenimento, cada plataforma em que uma história é contada torna-se um ponto de contato. Xavier (2015) fala como uma história pode percorrer diferentes mídias utilizando o exemplo de uma história romântica.

[...] ela pode ser lida em livro, em fascículos, em capítulos publicados em revistas ou jornais [...], em computadores, tablets, celulares, ou em cartazes colados pela cidade. [...] Seu filme vai passar no cinema, na televisão, [...] ganhará versão em DVD e, se for o caso, será fatiado como web série e/ou série de TV. (XAVIER, 2015, p. 260)

Todas as mídias citadas podem fazer parte dos pontos de contato do entretenimento. Filmes, livros, games e histórias em quadrinhos, por exemplo, são utilizados para propagar histórias, conforme exemplos da figura 5 . 
Figura 5 - Produtos do entretenimento

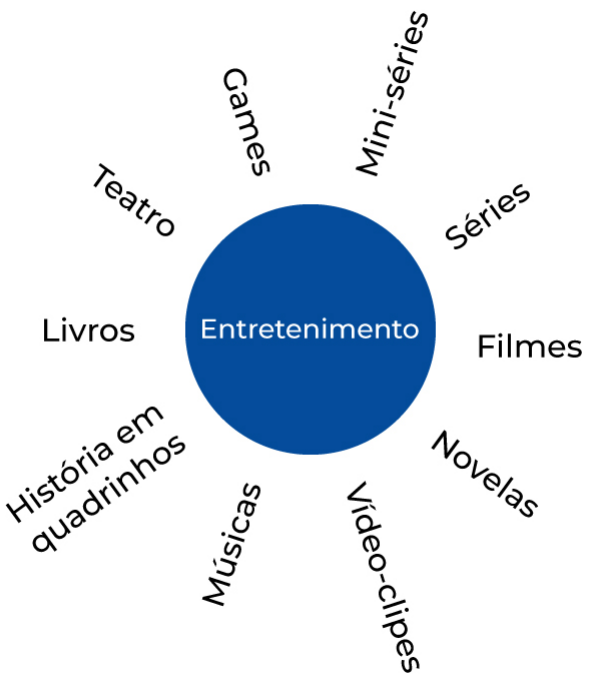

Fonte: da autora, 2019

Para Palacios e Terenzzo (2016, p. 190), "o entretenimento vive de histórias" e, o ato de contar uma história, permite utilizar tanto o ambiente corporativo quanto o cultural.

[...] vamos ao cinema e desligamos o celular. Ficamos hipnotizados diante da TV nos episódios de um seriado favorito. Passamos a madrugada em um game online. Não vemos a hora até o próximo episódio da novela, do capítulo do livro ou série favorita. (PALACIOS; TERENZZO, 2016, p. 206)

A televisão, por exemplo, é um dos meios de comunicação de massa que consegue atingir diversos públicos com sua variedade de conteúdos (VERONEZZI, 2009). O entretenimento apresenta-se nesse veículo por meio de novelas, filmes (geralmente importados pelas emissoras) e séries televisivas. Segundo a Pesquisa Brasileira de Mídia de 2016², realizada pela Presidência da República, 77\% dos entrevistados assistem a televisão nos sete dias da semana, revelando que a televisão é um veículo com grande poder no Brasil.

Contudo, diferente da televisão, o cinema, principalmente o norte-americano, utiliza a arrecadação das bilheterias para arcar com suas produções bilionárias. O cinema, ameaçado pelo crescimento da televisão e do streaming, mostra-se uma referência para outras mídias (XAVIER, 2015), com suas produções meticulosas e filmes sequenciais.

Na internet, Palacios e Terenzzo (2016) destacam que a frase "uma câmera na mão e uma ideia na cabeça" é um lema que reflete a produção de conteúdo nesse meio. Com a participação de produtoras e a mídia colaborativa, na internet, qualquer pessoa pode ter a oportunidade de se tornar uma celebridade. Além dos vídeos, o entretenimento na internet possui diversos formatos, sendo textos, como as fanficitions (histórias criadas por fãs), e imagens animadas (chamados gifs) ou não. Para Kotler, Kartajaya e Setiawan (2017, p. 57), "Com novos conteúdos sendo criados a cada segundo, a internet está se tornando mais rica e útil, o que beneficiará os usuários e atrairá os não usuários.".

Os serviços de Streaming, que funcionam por meio da internet, por exemplo, se expandem e ganham novos usuários a cada dia. A premissa é de que, ao estar conectado à internet, o usuário pode ter acesso a todo o catálogo de filmes, séries e documentários, sem comerciais e com total flexibilidade para pausar, pular e voltar o que estiver assistindo. Uma empresa desse segmento é a Netflix, com 139 milhões de assinantes em 190 países $^{2}$.

\footnotetext{
${ }^{1}$ Disponível em: http://pesquisademidia.gov.br/files/E-Book PBM 2016.pdf. Acesso em: 09 de abril de 2019

${ }^{2}$ Fonte: https://media.netflix.com/pt br/about-netflix. Acesso em: 13 de abril de 2019.
} 
O mercado editorial, por sua vez, destaca-se de diversas maneiras, pois é aquele em que estão inclusos os livros, revistas, jornais e as histórias em quadrinhos. O cenário dos quadrinhos segue em constante crescimento entre os meios editoriais e no mercado nacional.

Primeiramente os quadrinhos tinham o seu apelo voltado para o público infantil, como os famosos gibis da Turma da Mônica. Com a maturidade do setor, e inclusive do leitor, foi possível conceber produções voltadas ao público adulto, como quadrinhos eróticos ou romances gráficos. (PALACIOS; TERENZZO, 2016, p. 202).

Desta forma, com o exemplo das histórias em quadrinhos e dos serviços de streaming, pode-se perceber que os mercados do entretenimento se movem e se expandem conforme o seu público. Assim, seja com as marcas, seja com o entretenimento, os pontos de contato só farão sentido se estes estiverem alinhados aos seus consumidores/audiência.

\section{COMPORTAMENTO DO CONSUMIDOR}

O alinhamento dos pontos de contato com seu público remete ao comportamento do consumidor e sua relação como fã de um produto de entretenimento, pois por meio do estudo de suas atitudes é possível compreender a sua relação com a mídia espontânea. Desta forma, o comportamento do consumidor será o assunto desta seção.

\subsection{Definições e características}

O comportamento do consumidor é um estudo capaz de definir os motivos pelos quais as pessoas gastam seu tempo, esforço e dinheiro em itens de consumo (SCHIFFMAN; KANUK, 2000). Desta maneira, tornase preciso compreender fatores que levam a esse comportamento para que se compreenda, também o sucesso das marcas e do entretenimento.

Segundo os autores Schiffman e Kanuk (2000), o termo consumidor é utilizado para definir dois tipos diferentes de perfis de consumo, o consumidor organizacional e o consumidor pessoal. O organizacional, como o nome presume, inclui organizações com e sem fins lucrativos, órgãos do governo e instituições civis. São aqueles consumidores que procuram a matéria-prima para seus produtos, equipamentos para seus serviços e outros componentes que compõem seus negócios (SCHIFFMAN; KANUK, 2000).

O consumidor pessoal, por sua vez, é aquele que compra para o seu próprio uso (uma escova de dentes, por exemplo) ou para sua casa (um sofá, por exemplo). No entanto, nem sempre o comprador será o usuário, ou o único usuário de um produto (SCHFFMAN; KANUK, 2000). Pensando nisso, Kotler (2000) define que o consumidor pessoal possui cinco papéis na decisão de compra, sendo o iniciador, influenciador, decisor, comprador e o usuário. O iniciador dá a sugestão da compra, enquanto o influenciador utiliza seu ponto de vista para influenciar na escolha. O decisor decide tudo o que diz respeito a compra (o que comprar, como comprar, onde comprar), o comprador realiza a compra e, ainda, o usuário, que utiliza o produto ou serviço.

Desta maneira, a tomada de decisões do consumidor varia de acordo com o tipo de compra, pois, a compra de um refrigerante, de um celular ou de um carro novo, por exemplo, possui tomadas de decisões distintas (KOTLER, 2000). O autor estabelece cinco etapas do comportamento de compra, começando pelo reconhecimento do problema, busca de informações, avaliação das alternativas, decisão de compra e o comportamento de compra (KOTLER, 2000).

Kotler ainda define que o consumidor é influenciado por fatores culturais, sociais, pessoais e psicológicos. Culturais, referentes aos seus valores, percepções e classes sociais; Sociais, como status e os grupos de referência, que englobam aqueles que são influências para o consumidor, como família e religião; Pessoais, como idade, ocupação e estilo de vida, e ainda, os fatores psicológicos, que incluem suas motivações, crenças e atitudes (KOTLER, 2000). 
Para Schiffman e Kanuk (2000), o comportamento do consumidor também aborda motivos racionais, que possuem parâmetros objetivos como tamanho, peso e preço, por exemplo, e, ainda, motivos emocionais, que incluem critérios pessoais e subjetivos (medos, vontades, desejos). Segundo Kotler (2000, p. 21), "Os consumidores estão não apenas buscando produtos e serviços que satisfaçam suas necessidades, mas também buscando experiências e modelos de negócios que toquem seu lado espiritual.".

Tratando-se de um produto de entretenimento, principalmente com a influência da internet, os consumidores passam a expressar suas motivações emocionais, influenciando outros. Segundo Kotler, Kartajaya e Setiawan (2017), na era da conectividade, as comunidades, que atuam como influências sociais para o consumidor, estabelecem suas atitudes de consumo. Desta maneira, "muitas decisões que parecem pessoais são essencialmente decisões sociais. " (KOTLER; KARTAJAYA; SETIAWAN, 2017, p. 80).

Utilizando Fournier e Lee, os autores Kotler, Kartajaya e Setiawan (2010) afirmam que existem três definições para as comunidades, sendo de pools, webse hubs. Os consumidores em pools são aqueles unidos por uma crença e a filiação a uma marca, mas que não interagem. As comunidades webs, no entanto, são movidas pelas interações, enquanto os consumidores em hubs criam uma base leal de fãs para uma figura, como um líder.

Desta maneira, para compreender as motivações do consumidor para a geração de mídia espontânea para um produto de entretenimento, é preciso entender o comportamento dos consumidores como fãs.

\subsection{0 consumidor como fã}

$\mathrm{Na}$ internet, os fatores sociais que envolvem os públicos/usuários podem ser observados como seguidores, amigos e fãs (KOTLER, 2017). Para Kotler, Kartajaya e Setiawan (2010), os consumidores de pools, webs e hubs são grupos de entusiastas pela marca que devem ser cultivados pelas empresas, intensificandose ao se tratar do entretenimento.

Para a indústria do entretenimento, os fãs são peças fundamentais, pois são aqueles que possuem admiração por figuras públicas, artistas ou aqueles ligados ao mundo do entretenimento (DICIO, 2019). Os fãs fazem o papel dos admiradores ou advogados de uma marca, envolvendo-se, comprometendo-se e sendo contrários aos seus opositores (KOTLER; KARTAJAYA; SETIAWAN , 2017). Para Jenkins (2009, p. 188), “Os fãs são o segmento mais ativo do público das mídias, aquele que se recusa a simplesmente aceitar o que recebe, insistindo no direito de se tornar um participante pleno".

Além de defender seus ídolos, filmes e séries favoritas, os fãs que se tornam advogados de marca são participantes ativos, pois são contadores de histórias que espalham notícias e utilizam suas mídias para expor o seu ponto de vista autêntico, fazendo um papel que a publicidade não é capaz de alcançar (KOTLER; KARTAJAYA; SETIAWAN, 2017).

O entretenimento possui intensidade, tratando-se dessa relação de fãs, por conta de seu envolvimento com as experiências que o seu produto pode gerar. Segundo Kotler, Kartajaya e Setiawan (2010, p. 37), "a experiência de um produto jamais é isolada. É o acúmulo das experiências individuais do consumidor que cria maior valor para o produto", assim, esses consumidores personalizam suas experiências de acordo com seus desejos e necessidades.

Xavier (2015) afirma que o sucesso de uma história é relativo a sua capacidade de envolver o público. Desta forma, geram-se pontos de interatividade e participação. A interação é limitada pela tecnologia, gerando diferentes graus, como "a televisão, que nos permite mudar de canal, até videogames, que podem permitir aos usuários intervir no universo apresentado" (JENKINS, 2009, p. 189). Enquanto, a participação, por sua vez, é ilimitada, mais controlada pelos consumidores do que pelos produtores de mídia (JENKINS, 2009). Com as possibilidades geradas nas mídias sociais na internet, Jenkins (2009) afirma que todos são participantes, mesmo que tenham diferentes graus de status e influência.

Dentro do entretenimento, Xavier (2015) afirma que cada história possui o seu universo, guiado pelo conjunto de códigos que a formam. Desta maneira, esse conjunto de códigos é o que identifica uma história, ajudando ainda na criação de pontos de contato para a mesma. 
Um grande exemplo de fãs de entretenimento que se envolvem com o universo de uma história encontra-se em Star Wars (Guerra nas Estrelas), uma saga que possui filmes, livros, histórias em quadrinhos e séries de animação, que desde 1977, conquista audiências ao redor do mundo.

Jenkins (2009) aborda Guerra nas Estrelas quando fala sobre a participação dos fãs da saga, evidenciando que muitos deles cresceram cercados pelos elementos dessa história, utilizando fantasias de personagens e brincando com sabres de luz de plástico. "Guerra nas Estrelas tornou-se uma "lenda" deles" (JENKINS, 2009, p. 187). A fascinação desses fãs, não somente daqueles que cresceram assistindo os filmes, mas também, daqueles que se tornaram fãs com os últimos lançamentos, inspira diferentes formas para a expansão do universo do entretenimento.

Pontos de contato e interação foram criados pensando nesse público de consumidores e fãs da saga, como a convenção de fãs anual Star Wars Celebration, criada exclusivamente para celebrar e trazer novidades de Guerra nas Estrelas ${ }^{3}$.

A fascinação por esse universo ficcional inspira novas formas de produção de conteúdo que partem do próprio público de fãs, uma vez que a internet possibilita um canal de distribuição fortíssimo para a produção amadora (JENKINS, 2009). Os fãs criam produções audiovisuais, fanfictions, ilustrações (chamadas de fanarts), teorias, memes (imagens de cunho humorístico), entre outros conteúdos, utilizando os códigos do universo que desejam representar. Esse público colaborativo utiliza suas mídias sociais, influenciando outros com suas atitudes (KOTLER; KARTAJAYA; SETIAWAN, 2010).

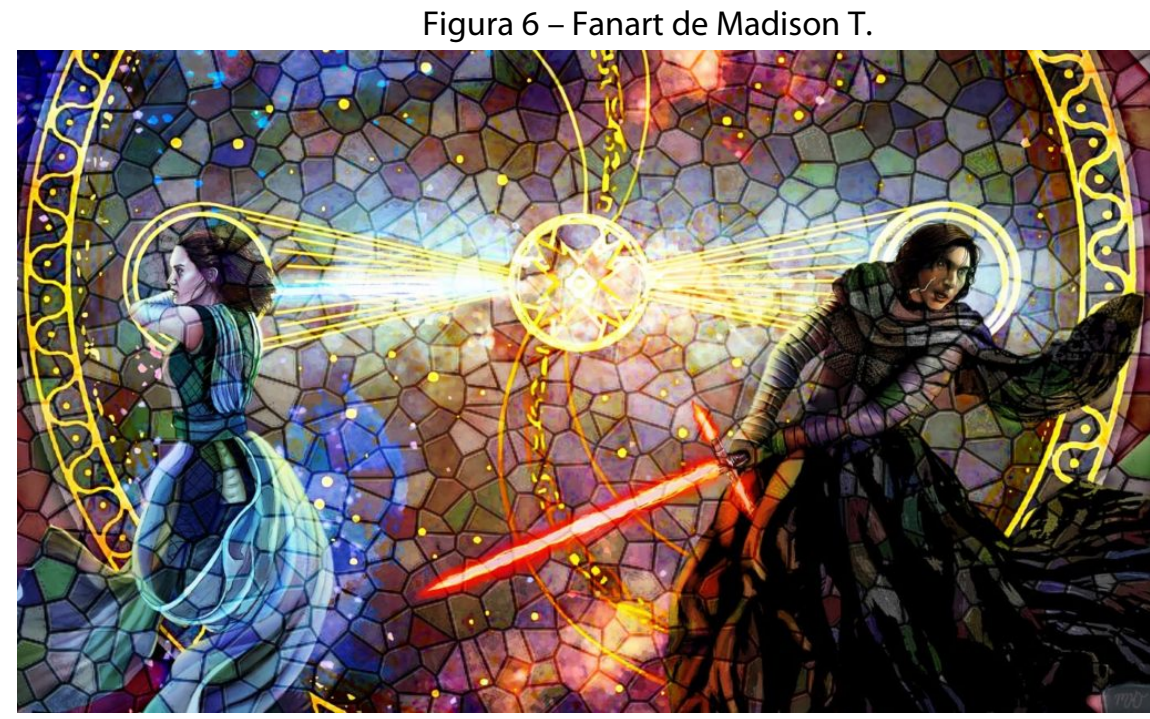

Fonte: STAR WARS (2019)

Essa criação de mídia espontânea não é exclusiva de uma saga como Guerra nas Estrelas, acontecendo com qualquer produto do entretenimento. Desta forma, ao compreender os conceitos de entretenimento, mídia espontânea e o comportamento do consumidor como fã, é possível analisar o caso proposto neste trabalho.

\section{ESTUDO DE CASO: ANALISANDO A SÉRIE THE UMBRELLA ACADEMY}

Após compreender os conceitos propostos para responder à pergunta problema deste artigo, iniciase a análise, que é um estudo de caso da série The Umbrella Academy.

\footnotetext{
${ }^{3}$ Fonte: https://www.starwarscelebration.com/About/FAQs/. Acesso em 14 de abril de 2019.
} 


\subsection{Sobre a série e parâmetros de análise}

The Umbrella Academyé uma série da plataforma de streaming Netflix, lançada em 15 de fevereiro de 2019. Dirigida por Steve Blackman, é uma adaptação da série de histórias em quadrinhos de mesmo nome, criada em 2007 por Gerard Way e Gabriel Bá, lançada originalmente pela editora Dark Horse Comics, nos Estados Unidos, com 3 edições (sendo que a primeira temporada da série é inspirada nas duas primeiras edições dos quadrinhos, pois a terceira edição foi lançada após o lançamento da série) e uma média de 192 páginas por edição.

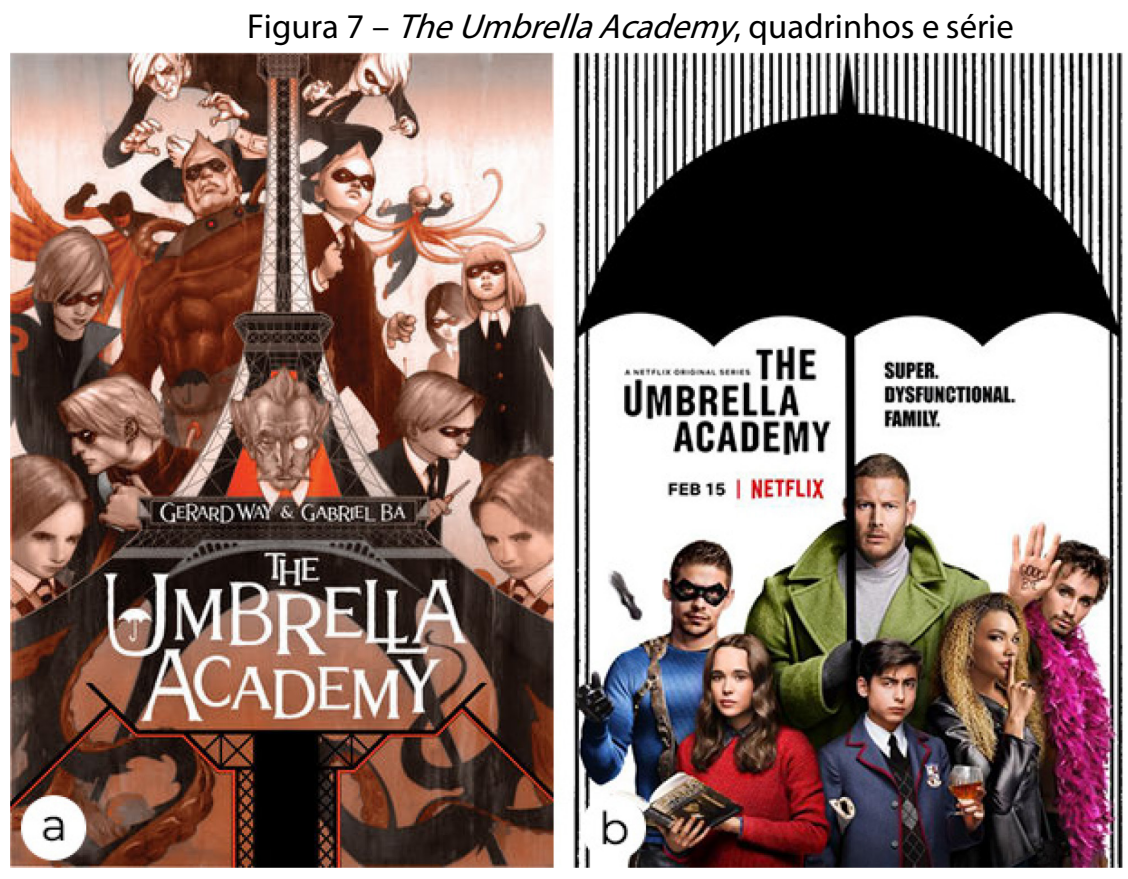

Fonte: 7a: COVRE (2017). 7b: CINEMA (2018)

Com dez episódios e uma duração média de 40 minutos, a série conta a história de um grupo de irmãos superpoderosos adotados por Sir Reginald Hargreeves, que, com a intenção de desenvolver os seus poderes e proteger o mundo de ameaças, os transforma no grupo de super-heróis chamado The Umbrella Academy. Com a misteriosa morte de Reginald, anos depois, os irmãos se reencontram e trabalham juntos para descobrir a causa da morte do pai adotivo, além de enfrentar uma ameaça iminente e inesperada: o fim do mundo.

Na série, assim como nas histórias em quadrinhos das quais se originou, cada irmão possui poderes e personalidades distintas. Na infância, após a adoção, Reginald lhes deu números como nomes. No entanto, a mãe adotiva (que é um robô construído por Reginald para essa finalidade) lhes deu nomes reais. O Número Um, ou Luther, é considerado o líder do grupo, sendo o maior dos irmãos e o mais fiel ao pai, possui super força. O Número Dois, conhecido como Diego, possui uma rivalidade com Luther e têm habilidade com sua mira, sendo que as facas são as armas que utiliza para acertar qualquer alvo. Allison, a Número Três, possui o poder de controlar pessoas mentalmente, usando a frase "Eu ouvi um boato". Ela possui uma forte ligação com Luther e tornou-se atriz, usando seus poderes de manipulação para chegar ao sucesso. Klaus, o Número Quatro, possui a habilidade de falar com os mortos, causando-lhe um trauma e o tornando viciado em drogas e álcool. O Número Cinco, com habilidades de viajar no tempo e espaço, é o único personagem que não possui um nome real, pois foi dado como desaparecido aos 13 anos. O Número Seis era conhecido como Ben, possuía tentáculos gigantes que saiam de seu peito e faleceu em um evento não mencionado. Finalmente, Vanya, ou a Número Sete, é a única dos irmãos que não demonstra poderes. Cresceu agindo como uma assistente para Reginald e não fazendo parte da Umbrella Academy. Possui habilidade com o instrumento violino, tornandose professora do instrumento na vida adulta. 
Figura 8 - Personagens de The Umbrella Academy

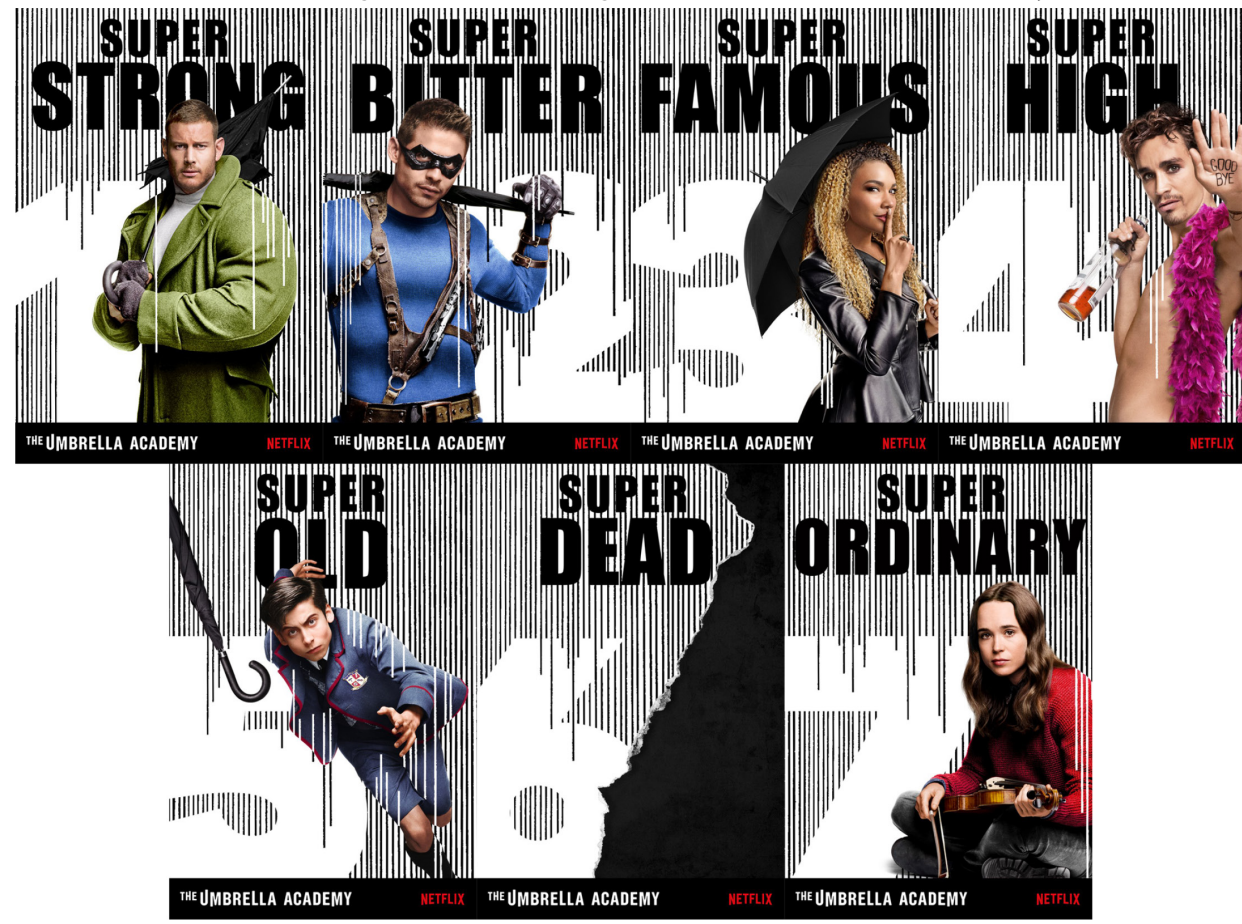

Fonte: GANIKO (2018). Adaptado pela autora.

Essa análise usa como parâmetro o período anterior e posterior ao lançamento da série na plataforma Netflix, de dezembro de 2018 a março de 2019, totalizando quatro meses. Como o objetivo trata a identificação de diferentes formas de publicação e divulgação espontâneas geradas pelo público da série, as mídias utilizadas serão Youtube, Facebook, Instagram, Twitter, sites pessoais e sites de entretenimento e notícias, levando em consideração para a análise até quatro publicações ou ações de cada mídia, sendo que a definição dessas se dá por convenção da autora, levando em consideração publicações com maior interação, que possuem a hashtag \# TheUmbrellaAcademye que estejam dentro da janela de pesquisa definida.

\subsection{Mídias proprietárias}

Para identificar a mídia espontânea gerada pelos fãs da série, faz-se necessário primeiramente distinguir sua mídia proprietária, aquela que, segundo Kotler e Armstrong (2007), a marca é capaz de controlar. Desta maneira, foram levantadas as ações de divulgação feitas pela Netflix que mais causaram interações, nos idiomas inglês e português, por meio de suas redes sociais no período definido pela janela de pesquisa.

A Netflix possui perfis em redes sociais, como Facebook, Instagram, Twitter e Youtube, tanto no idioma inglês quanto português. A primeira ação identificada foi o lançamento de um teaser trailer, que consiste em uma pequena versão do traileroficial, em 8 de dezembro de 2018. O lançamento do teaserse deu durante o painel da série na Comic Con Experience, evento que acontece no Brasil e contou com a presença dos atores e produtores da série, com destaque para Gerard Way, autor dos quadrinhos que originaram a série e ex-vocalista da banda My Chemical Romance, além da atriz Ellen Page, que apareceu no evento sem ter sido anunciada.

Entretanto, alguns pôsteres da série já haviam sido divulgados, assim como a criação dos perfis oficiais da série no Instagram, Twitter e Facebook, conforme figura abaixo, possibilitando uma divulgação e interação (apenas em língua inglesa) focada no conteúdo da série. 
Figura 9 - Perfis da série nas redes sociais
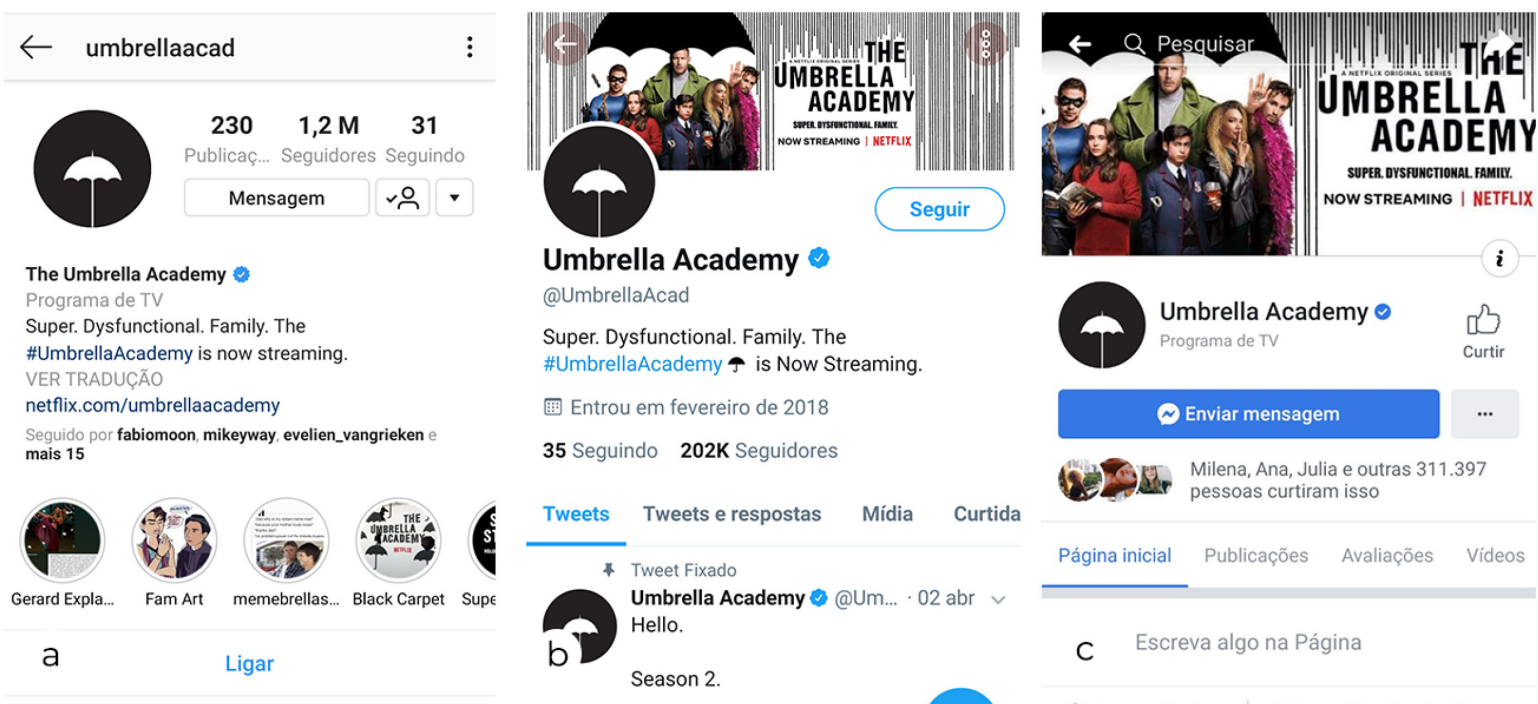

C Escreva algo na Página

Fonte: 9 a. THE UMBRELLA ACADEMY (2019). 9 b. UMBRELLA ACADEMY (2019). 9 c. UMBRELLA

ACADEMY (2019)

Além disso, durante o período proposto nessa análise, algumas ações feitas pela marca destacam-se por seu número de visualizações, como a divulgação do trailer oficial em 24 de janeiro de 2019, que alcançou em torno de 5 milhões de visualizações até maio de 2019, período de produção desta análise, e o lançamento de uma das músicas da trilha sonora, um coverda música Hazy Shade Of Winter (originalmente da dupla Simon \& Garfunkel) gravada por Gerard Way e com participação de Ray Toro (ambos ex-membros da banda My Chemical Romance), que alcançou 4 milhões de visualizações no canal oficial do cantor Gerard Way no YouTube.

Ainda, com foco no público brasileiro, a Netflix lançou um vídeo promocional em que a jogadora de futebol Marta, após supostamente anunciar uma pausa na carreira para se dedicar a família em suas redes sociais, acabou por se tornar a irmã número 10 da família de super-heróis.

Figura 10 - Ação com a jogadora marta

\section{Nada de pausa: post misterioso de Marta não passa de ação da Netflix}
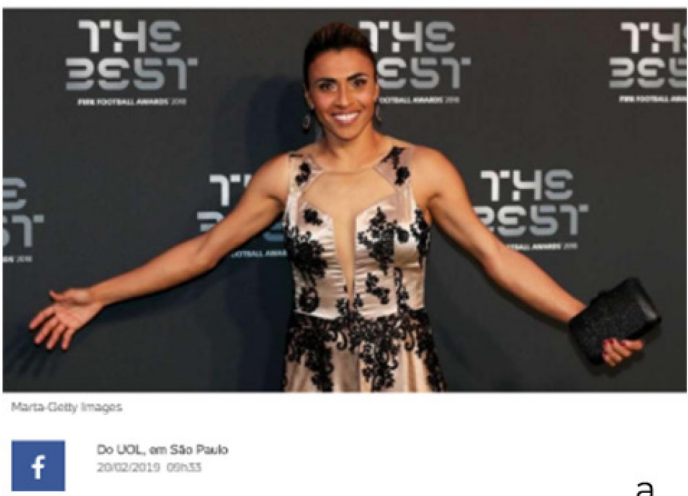

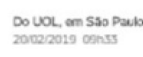

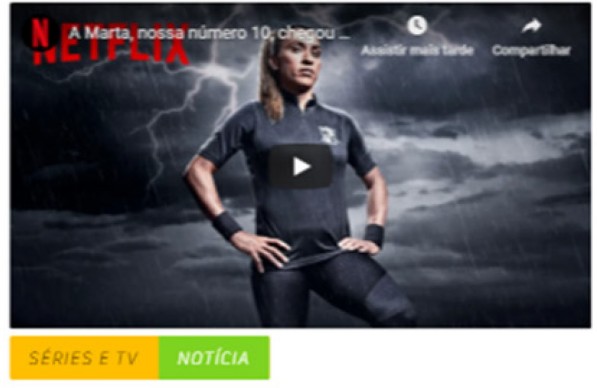

The Umbrella Academy I Jogadora Marta entra para família em comercial

Fonte: 10 a. UOL (2019); 10. B. SABBAGA (2019).

Além das ações levantadas, os perfis oficiais fazem publicações para gerar engajamento com o público, como recortes de momentos da série, postagens de cunho humorístico e notícias relacionadas aos 
atores e produtores. O perfil da série no Twitter utiliza a hashtag \#TheUmbrellaAcademy, sendo um incentivo para os seguidores do perfil.

Com o lançamento da série na plataforma, em 15 de fevereiro de 2019, é possível perceber o ganho de notoriedade por meio do interesse em pesquisas no Google, por meio de gráficos gerados na plataforma Google Trends, que mostra o interesse por termos de pesquisas em períodos específicos. Ao definir o período explorado nessa análise, observa-se que entre 17 e 23 de fevereiro de 2019 há um pico no número de procuras no gráfico, que remete ao lançamento da série.

Figura 11 - Interesse de pesquisa do termo The Umbrella Academy

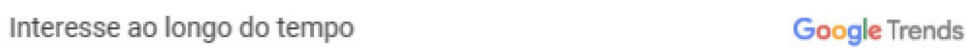

the umbrella academy

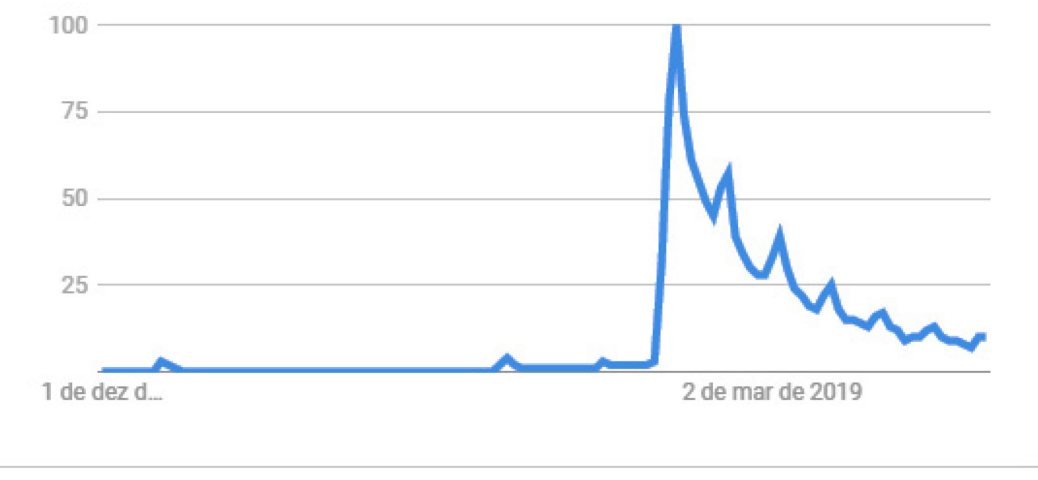

Todo o mundo. 01/12/2018 - 31/03/2019. Pesquisa Google na Web.

Fonte: GOOGLE TRENDS (2019)

Desta forma, após o levantamento de ações realizadas pela Netflix e a verificação do interesse pela série por meio da pesquisa realizada na plataforma Google Trends, realiza-se a identificação das diferentes formas de mídia espontânea criadas pelo público da série.

\subsection{Mídias espontâneas}

Ao iniciar a análise pelo Youtube, percebe-se que existem inúmeros canais voltados ao conteúdo de entretenimento. Quatro vídeos sobre a série foram identificados para a análise, revelando que, enquanto algumas pessoas expressam suas opiniões a respeito de temas relevantes para o seu público, outras geram vídeos mostrando suas ideias e levantando argumentos com novas possibilidades para o produto em questão. O primeiro vídeo, demonstrado na figura 12 a, mostra a opinião de uma pessoa influente (de acordo com o seu número de visualizações e seguidores) a respeito da série, falando sobre a relação entre super-heróis dentro da plataforma Netflix. O segundo vídeo, da figura 12 b, é um comparativo entre a série e as histórias em quadrinhos, reforçando a relação entre os dois produtos. No terceiro vídeo, representado pela figura 12 c, por sua vez, a apresentadora do canal levanta teorias sobre o que aconteceu com Ben, ou Número Seis, que faleceu sobre circunstâncias não reveladas durante a primeira temporada da série. Assim, no quarto vídeo, da figura $12 \mathrm{~d}$, Natalia, do canal "Kreuser tipo Freud" explica o final da primeira temporada da série e fala sobre o que esperar da segunda temporada, que ainda não havia sido confirmada pela Netflix na data de publicação do vídeo, em 17 de fevereiro de 2019. 
Figura 12 - Vídeos no Youtube sobre The Umbrella Academy

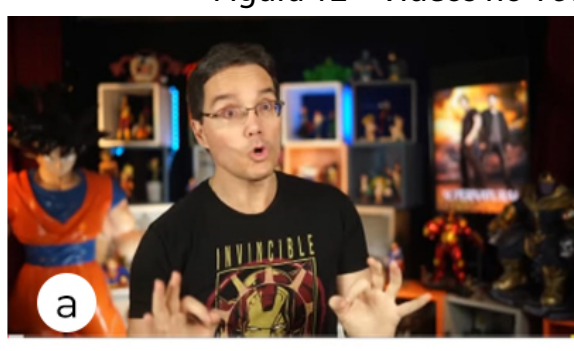

\#UmbrellaAcademy \#Netflix \#Serie UMBRELLA ACADEMY: NETFLIX NÃO A PRECISA DA MARVEL

481.681 visualizações

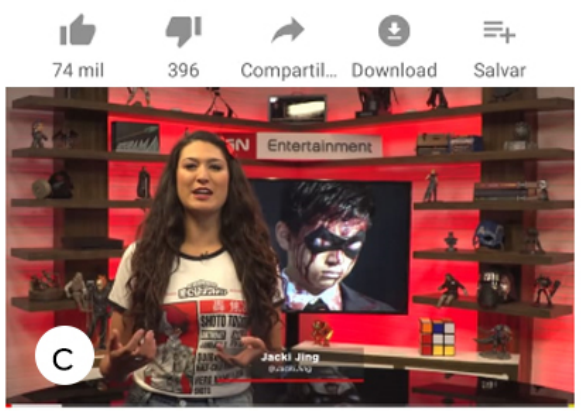

\#ign \#umbrellaacademy Umbrella Academy: What Happened to Ben?

1.872.074 visualizações

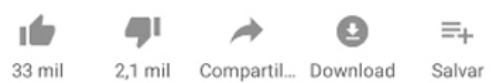

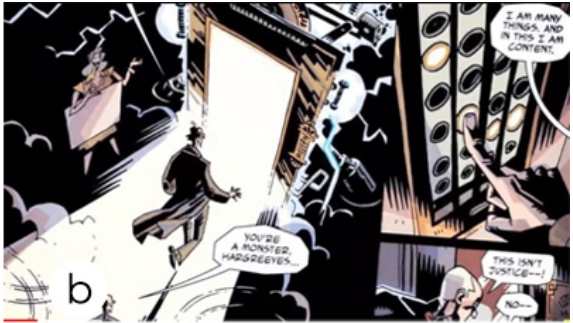

\#umbrellaacademy \#ellenpage \#apocalypsesuite The Umbrella Academy The Biggest Differences Between The Netflix Show ...

379.461 visualizações
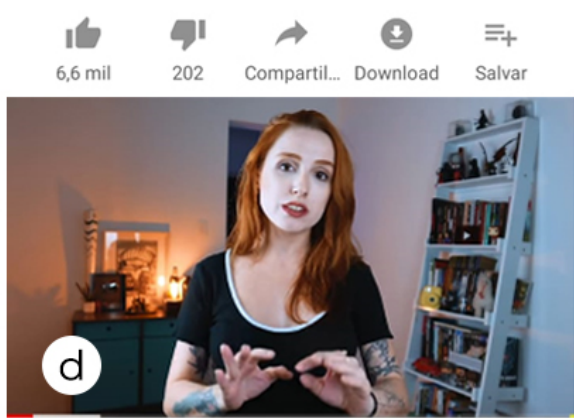

\#TheUmbrellaAcademy \#FinalExplicado \#Netflix THE UMBRELLA ACADEMY Final Explicado $+2^{\mathrm{a}}$ Temporada

114.066 visualizaçōes

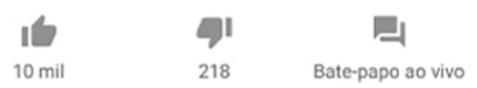

Fonte: 12 a. JORDAN (2019); 12 b. THETHINGS (2019); 12 c. IGN (2019); 12 d. KREUSER (2019).

Com a identificação dos vídeos e a participação plena desses criadores de conteúdo, é possível perceber a aplicação da afirmação de Xavier (2015), quando afirma que uma história só é bem-sucedida quando o público está dentro dela. Assim, Ferrari (2015), diz que as mídias sociais permitem a cooperação e o compartilhamento de experiências, o que também remete a criação de comunidades segmentadas por interesses. Em relação a série, essas comunidades podem ser observadas por meio do Facebook, pois a rede social permite a criação de grupos de discussão.

Assim, foram levantados os quatro principais grupos sobre a série no Facebook, de acordo com o número de participantes, por meio da ferramenta da barra de pesquisa da rede social. O maior grupo com "The Umbrella Academy" no nome possui 26 mil membros, com uma média de 10 publicações por dia, conforme figura abaixo. 
Figura 13 - Grupos sobre The Umbrella Academyno Facebook

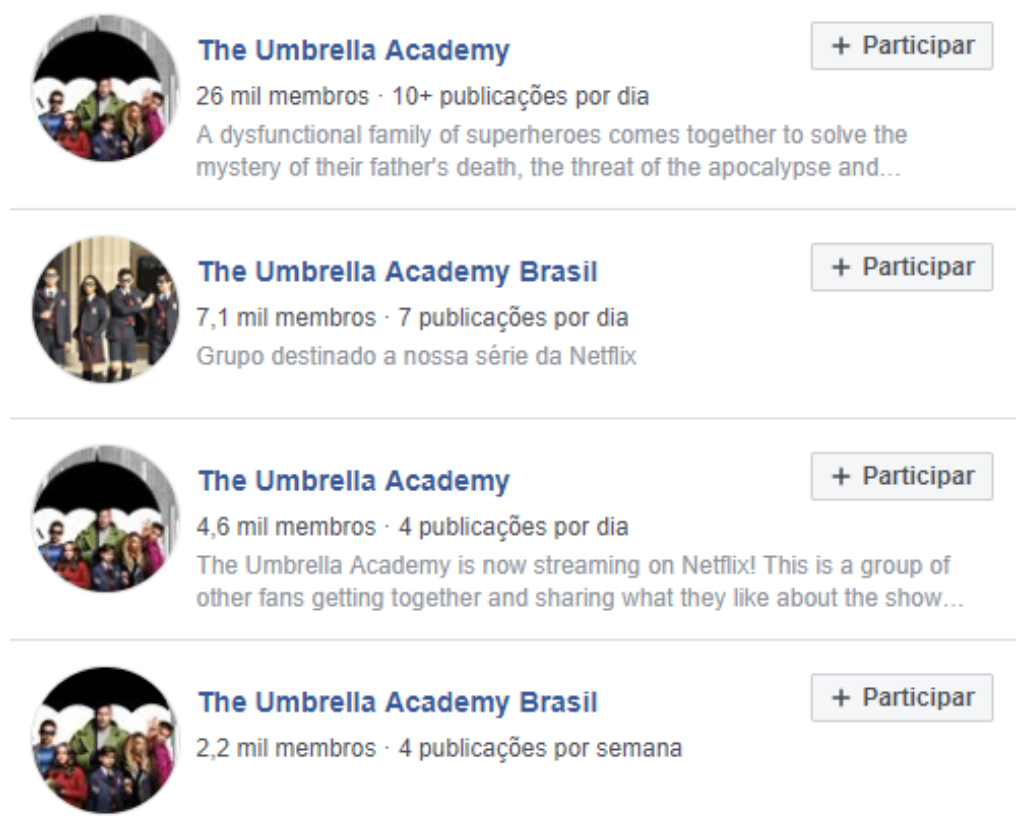

Fonte: FACEBOOK (2019)

Como mencionado anteriormente, a criação dessas comunidades permite o compartilhamento de experiências, assim como discussões, que podem influenciar a geração de mais conteúdo. No entanto, a mídia espontânea não se limita a grupos sociais, acontecendo também em perfis pessoais, como é o caso do Instagram.

Por meio do Instagram, tratando-se de uma rede social com foco em vídeos e imagens, é possível identificar a mídia espontânea criada pelos fãs utilizando elementos de identificação da série. Segundo a afirmação de Xavier (2015) cada história é guiada pelo conjunto de códigos que a formam, e isso identifica seu universo. Ao aplicar esse conceito a The Umbrella Academy, é possível afirmar que a série é repleta de elementos e símbolos que constroem o estilo e fazem sua diferenciação. Pode-se observar tais elementos em dois tipos de mídia espontânea compartilhada no Instagram: as Fanartse os Cosplays.

As Fanarts escolhidas utilizam códigos criados pela série para a identificação de personagens, como na figura $14 \mathrm{a}$, onde o personagem Cinco aparece com o uniforme da Umbrella Academy, por exemplo. Na figura $14 \mathrm{~b}$, os personagens aparecem caminhando, trajados com suas roupas características e em ordem numérica, da Número Sete para o Número Um. A utilização dos códigos permite com que os artistas possam empregar os seus próprios estilos nas ilustrações, mas sem perder as características que fazem a conexão ao universo da série. 
Figura 14 - Fanarts de The Umbrella Academy
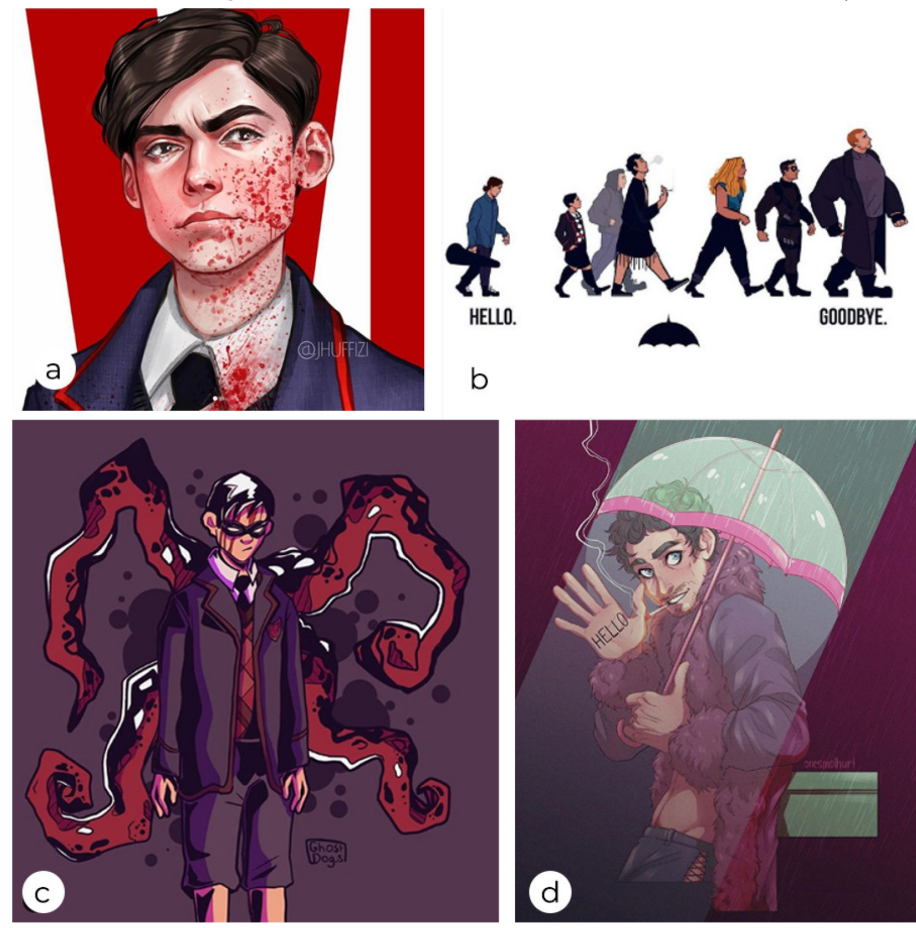

$b$

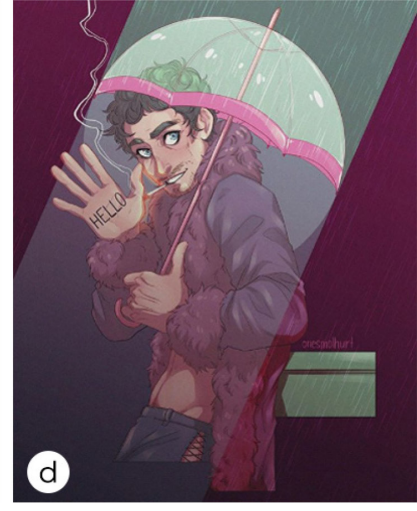

Fonte: Fonte: 4 a. JHU (2019); 12 b. AL (2019); 12 c. SERY (2019); 12 d. ONESMOLHURT (2019). Adaptado pela autora.

Outro exemplo são os Cosplays, quando os fãs se caracterizam como os personagens e dão vida aos mesmos. Essa caracterização só é possível graças aos códigos utilizados pela série, como por exemplo, na figura 15 b, onde pode-se perceber que a fã está caracterizada como a personagem Número Sete (Vanya), graças ao terno e violino utilizados no figurino.

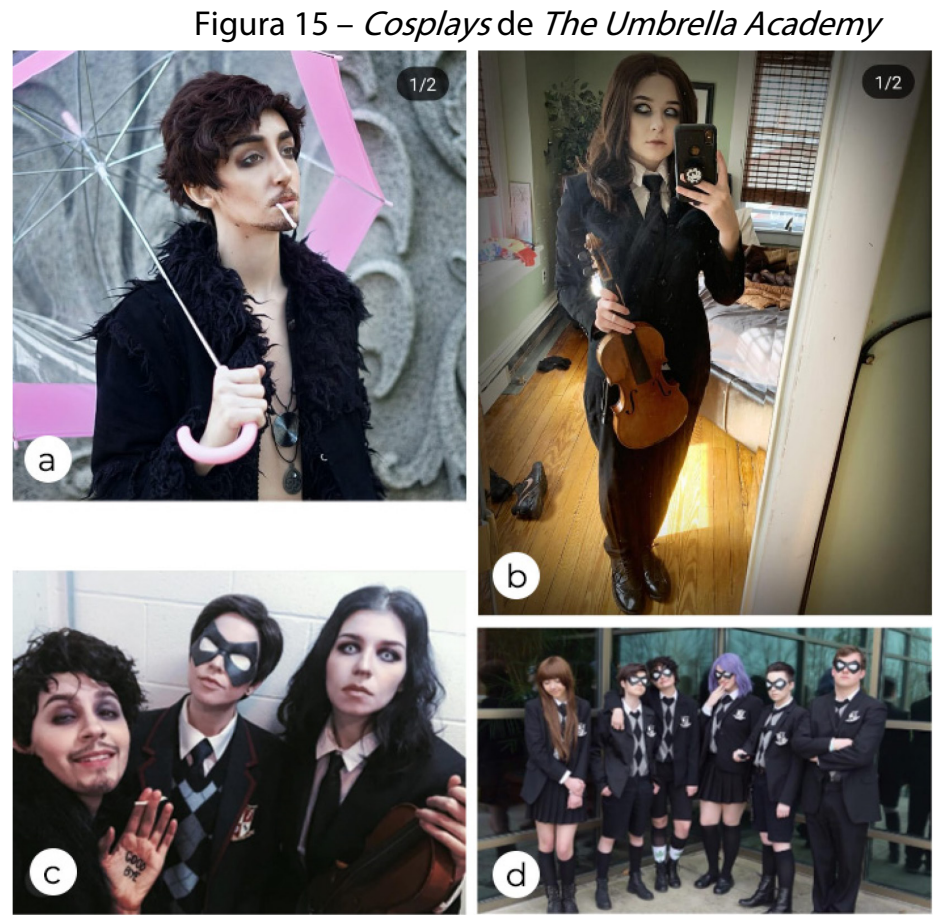

Fonte: Fonte: 13 a. MIKA (2019). 13 b. DWIMPLEPEEN (2019); 13 c. ESTRADA (2019); 13 d. BAN (2019). Adaptado pela autora. 
Graças a liberdade para expressar ideias na internet, os fãs podem criar e idealizar diferentes perspectivas para a narrativa, criando personagens, descrevendo acontecimentos e explorando possibilidades. Além de ilustrações e cosplays, as fanfictions também fazem parte do universo da mídia espontânea da série. Ao pesquisar por "The Umbrella Academy" no Wattpad, plataforma para disponibilização de fanfictions com 70 milhões leitores ${ }^{4}$, por exemplo, foram encontradas 153 histórias criadas por fãs com base na história da série e dos quadrinhos de The Umbrella Academy.

Além do que é criado pelos fãs, o "boca a boca" também acontece em outras mídias da internet, como sites e blogs de notícias e entretenimento. Ao realizar uma pesquisa no Google dentro do período proposto nessa análise, é possível perceber que, além de notícias relacionadas ao lançamento da série, diversos sites abordam análises e críticas a respeito dos episódios, comparações com as histórias em quadrinhos e entrevistas com atores e produtores da série.

Um exemplo é a crítica publicada pelo site Omelete ${ }^{5}$, que diz que "Adaptação das HQs de Gerard Way e Gabriel Bá traz família heroica disfuncional em série excêntrica e cheia de personalidade".

Dessa forma, ao identificar os diferentes tipos de mídia espontânea geradas para a série The Umbrella Academy, é possível prosseguir para os resultados obtidos nessa análise.

\subsection{Discussão dos resultados}

Como citado anteriormente, Jenkins (2009) define a diferença entre a interação e a participação, sendo que a participação é aquela que é controlada pelo público. Kotler, Kartajaya e Setiawan (2010) também afirmam que a experiência do consumidor cria mais valor para um produto, assim, ao atrelar essas afirmações, é possível retomar a questão principal deste artigo e compreender a amplitude gerada para a série The Umbrella Academy por meio da mídia espontânea.

Após a identificação dos diferentes tipos de mídia espontânea geradas pelo público, é possível perceber que a criatividade do mesmo, assim como a quantidade de conteúdos criados gerados, podem acrescentar ao universo da série The Umbrella Academy como possíveis pontos de contato pois, para Wheeler (2012), os pontos de contato são oportunidades para aumentar o conhecimento e promover a fidelidade do cliente para com a marca. Desta maneira, quando o público espectador da série interage e participa da criação de novos pontos de contato, o universo da série, com todos os seus símbolos, se expande, gerando a amplitude observada por meio dessa análise e resultando na figura a seguir.

Figura 16 - O universo de divulgação de The Umbrella Academy

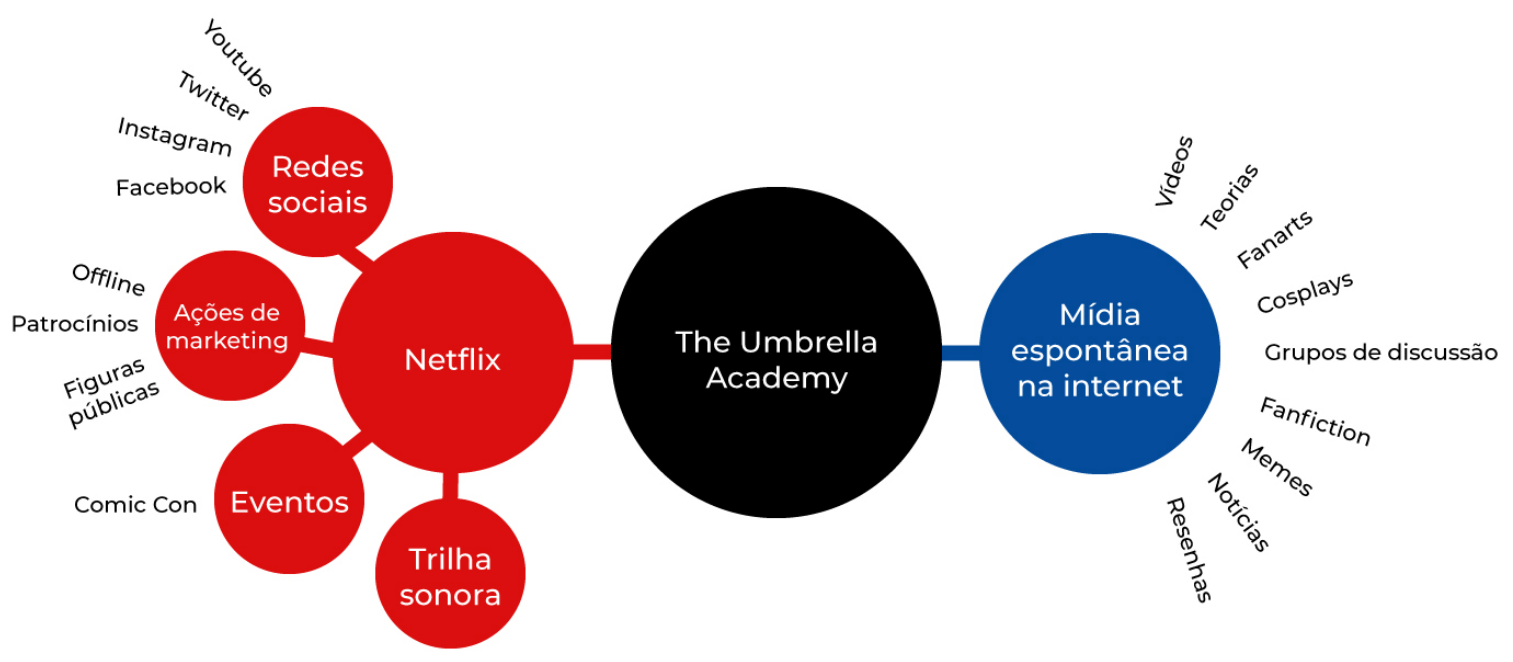

Fonte: da autora (2019).

\footnotetext{
${ }^{4}$ Fonte: https://www.wattpad.com/.

${ }^{5}$ Fonte: https://www.omelete.com.br/series-tv/criticas/the-umbrella-academy-1a-temporada
} 
Graças aos fãs e a geração de mídia espontânea, o cenário constituído para divulgação da série ultrapassa o que é proposto inicialmente pela emissora/plataforma Netflix, sendo criados pontos de contato que fortalecem esse produto de entretenimento perante os fãs.

É possível perceber, por meio dessa análise, que a criação desses pontos só é possível pois todas as plataformas analisadas dão a audiência a liberdade para criar o seu próprio conteúdo a partir do que lhes foi entregue pela emissora/plataforma, assim, tornando-os participantes plenos, conforme a definição de Jenkins (2009), expondo seus pontos de vista autênticos e ainda, segundo Kotler (2017), tomando para si um papel que a publicidade não é capaz de atingir.

\section{CONSIDERAÇÕES FINAIS}

O presente artigo pôde responder, por meio de seus objetivos específicos, a pergunta problema proposta: "Como a mídia espontânea pode gerar amplitude para um produto de entretenimento? ". Para isso, os objetivos foram definidos de maneira a guiar a pesquisa e análise deste trabalho, para que o resultado proposto fosse alcançado.

O principal objetivo da pesquisa, que tinha como característica identificar diferentes formas de publicação e divulgação geradas pelo público consumidor de entretenimento por meio da mídia espontânea, foi apresentado em diferentes sessões deste trabalho. Inicialmente, na sessão 2.1 do capítulo 2, em que se dá a definição de mídia espontânea; em seguida, na sessão 3.2 do capítulo 3, que apresenta a mídia espontânea como pontos de contato criados pelos consumidores fãs de um produto de entretenimento e, ainda, na análise deste artigo, que utilizou os conceitos apresentados para identificar a mídia espontânea criada para a série The Umbrella Academy.

Entre os objetivos específicos, este trabalho relacionou os pontos de contato presentes no entretenimento, na sessão 2.2 do capítulo 2 , e identificou o comportamento do consumidor que os leva a ser propagadores de uma marca, apresentando o conceito do consumidor como fã na sessão 3.2 do capítulo 3 .

Por fim, após o entendimento de tais conceitos, o estudo de caso proposto pôde ser trabalhado por meio da análise realizada no quarto capítulo, a divulgação feita pela Netflix e as criações espontâneas geradas pelo público consumidor da série foram identificadas, podendo gerar a relação entre as duas mídias e identificando-as como pontos de contato.

Dessa forma, retomando a pergunta problema, por meio da análise realizada e dos conceitos apresentados, foi possível concluir que a amplitude pode ser gerada a partir da mídia espontânea quando o público é participativo, segundo a definição de Jenkins (2009), utilizando a liberdade criativa das mídias para criar pontos de contato que não foram previamente definidos pela marca e que nem podem ser produzidos pela mesma, por tratar-se da perspectiva do consumidor.

Com a intenção de acrescentar conteúdo aos estudos sobre mídia espontânea e pontos de contato, esse trabalho pode agregar para pesquisas futuras sobre os temas abordados. Como sugestões, mais estudos podem ser realizados sobre a mídia espontânea na internet, assim como a criação de pontos de contato para diferentes produtos, seja de entretenimento ou para marcas em geral, demonstrando a importância de tais temas e possibilitando diferentes abordagens, principalmente em questão às possibilidades criadas por meio da internet.

\section{REFERÊNCIAS}

AL. I think we're alone now. Depok, 23 de fev. 2019. Instagram: @altheweirdguy. Disponível em: https://www.instagram.com/p/BuN9xyDAoei/. Acesso em: 4 maio 2019.

BAN. Cosplay dos personagens de The Umbrella Academy. Carolina do Norte, 29 de mar. 2019. Instagram: @ban.cos. Disponível em: https://www.instagram.com/p/BvmwqBCH29m/. Acesso em: 4 maio 2019. 
BLUME, Marcelo. Promoção, propaganda e mídia. ljuí: Editora Unijuí, 2009. Disponível em: http://bibliodigital.unijui.edu.br:8080/xmlui/bitstream/handle/123456789/195/Promo\%C3\%A7\%C3\%A3o,\%2 Opropaganda\%20e\%20m\%C3\%ADdia.pdf?sequence=1 Acesso em: 17 mar. 2019.

CANFIELD, Daniel de Salles; GALLON, Shalimar; CORTE, Vitor Francisco Dalla. O Design Thinking na jornada do consumidor em uma steakhouse no Brasil. Piracicaba: Caderno Profissional de Marketing - UNIMEP, 2017. Disponível em:

https://www.cadernomarketingunimep.com.br/ojs/index.php/cadprofmkt/article/view/79/89. Acesso em: 8 abr. 2019.

CHINEM, Rivaldo. Marketing e divulgação da pequena empresa: como o pequeno e o microempresário podem chegar à mídia. São Paulo: Senac, 2017. Disponível em: https://books.google.com.br/books?id=gskDwAAQBAJ\&printsec=frontcover\&hl=pt-BR\&source=gbs ge summary $r \& c a d=0 \# v=$ onepage\&q\&f=false. Acesso em: 13 de março de 2019.

CINEMA, Adoro. The Umbrella Academy: Poster. [S. I.: s. n.], 9. dez. 2018 Disponível em: http://www.adorocinema.com/series/serie-22367/foto- detalhada/?cmediafile=21576648. Acesso em: 5 maio 2019.

COVRE, Giulia. The Umbrella Academy. [S. I.: s. n.], 6 jul. 2017. Disponível em: https://www.papelpop.com/2017/07/hq-de-gerard-way-do-my-chemical-romance-pode- virar-serie-danetflix/the-umbrella-academy/. Acesso em: 5 maio 2019.

DICIO. Dicionário Online de Português, definições e significados de mais de $\mathbf{4 0 0}$ mil palavras. Todas as palavras de A a Z. Disponível em: https://www.dicio.com.br/ Acesso em: 11 abr. 2019.

DWIMPLEPEEN. Hello Goodbye. Alemanha, Nova Jersey, 14 de mar. 2019. Instagram: @genovere. Disponível em: https://www.instagram.com/p/BvAJKTHHzSc/. Acesso em: 4 maio 2019.

ESTRADA, Carmen Valentina. Umbrella Fam. Montreal, 10 mar. 2019. Instagram: @carmenvalentina. Disponível em: https://www.instagram.com/p/Bu1mqGHIQ9X/. Acesso em: 4 maio 2019.

FACEBOOK. The Umbrella Academy - Pesquisa do Facebook. 2019. Disponível em: https://www.facebook.com/search/groups/?q=the\%20umbrella\%20academy\&epa=SERP_TAB. Acesso em: 4 maio 2019.

FERRARI, Pollyana. A força da Mídia Social: interface e linguagem jornalística no ambiente digital. São Paulo: Estação das Letras e Cores, 2015.

GANIKO, Priscila. Umbrella Academy ganha novos pôsteres focados em personagens: Nove pôsteres no total. [S. I.: s. n.], 5 out. 2018. Disponível em: https://jovemnerd.com.br/nerdbunker/umbrella-academyposteres/. Acesso em: 28 abr. 2019.

GASPARY, Marianne Barbosa. Design de pontos de contato: a experiência de marca na área de moda. Porto Alegre: Universidade Federal do Rio Grande do Sul, 2013. Disponível em: https://lume.ufrgs.br/handle/10183/95530. Acesso em: 8 abr. 2019.

GOOGLE TRENDS. Pesquisa do termo "The Umbrella Academy”. Disponível em: https://trends.google.com/trends/explore?date=2018-01-12\%202019-0331\&q=The\%20Umbrella\%20Academy. Acesso em: 28 abr. 2019.

IGN. Umbrella Academy: What Happened to Ben?. 2019. (6m13s). Disponível em: https://youtu.be/ZwP3Ukq_KFQ. Acesso em: 4 maio. 2019.

JENKINS, Henry. Cultura da Convergência. São Paulo: Aleph, 2009. 
JHU. Ilustração do personagem Cinco da série The Umbrella Academy. Rússia, 6 de mar. 2019. Instagram: @jhuffizi. Disponível em: https://www.instagram.com/p/BurY_psF9dc/. Acesso em: 4 amio 2019.

JORDAN, Peter. Umbrella Academy: Netflix não precisa da Marvel. 2019. (9m55s). Disponível em: https://www.youtube.com/watch?v=Tlvor5OooFE\&amp;t=3s. Acesso em: 4 maio 2019.

KOTLER, Philip. Administração de marketing: a edição do novo milênio. São Paulo: Prentice Hall, 2000.

KOTLER, Philip; ARMSTRONG, Gary. Princípios de Marketing. São Paulo: Pearson Prentice Hall, 2007.

KOTLER, Philip; KARTAJAYA, Hermawan; SETIAWAN, Iwan. Marketing 3.0. Rio de Janeiro: Elsevier, 2010.

KOTLER, Philip; KARTAJAYA, Hermawan; SETIAWAN, Iwan. Marketing 4.0. Rio de Janeiro: Sextante, 2017.

KREUSER, Natalia. The Umbrella Academy Final Explicado + 2a Temporada. 2019. (5m14s). Disponível em: https://youtu.be/qZMHY-rkDjQ. Acesso em: 4 maio 2019.

MIKA. Best. Funeral. Ever. Chicago, 25 de mar. 2019. Instagram: @_putrid. Disponível em: https://www.instagram.com/p/BvcGWXqDwPA/. Acesso em: 4 maio 2019.

ONESMOLHURT. Hello Goodbye. Alemanha, 9 de mar. 2019. Instagram: @onesmolhurt. Disponível em: https://www.instagram.com/p/BuzP3Fcnzks/. Acesso em: 4 maio 2019.

PALACIOS, Fernando. TERENZZO, Martha. O guia completo do Storytelling. Rio de Janeiro: Alta Books, 2016. PEREIRA, Vinicius Andrade. Entretenimento como Linguagem e Multissensorialidade na Comunicação Contemporânea. Manaus: Intercom - Sociedade Brasileira de Estudos Interdisciplinares da Comunicação XXXVI Congresso Brasileiro de Ciências da Comunicação, 2013. Disponível em: http://www.intercom.org.br/papers/nacionais/2013/resumos/R8-1691-1.pdf. Acesso em: 17 mar. 2019.

PRICEWATERHOUSECOOPERS BRASIL. 19 Pesquisa Global de Entretenimento e Mídia 2018-2022. Brasil, 2018.Disponível em: https://www.pwc.com.br/pt/outlook-18.html. Acesso em: 01 abr. 2019.

RAUEN, Fábio José. Roteiros de iniciação científica: os primeiros passos da pesquisa científica desde a concepção até a produção e a apresentação. Palhoça: UNISUL, 2015.

ROCHA, Rose de Melo; CASTRO, Gisela G. S.. Cultura da mídia, cultura do consumo: imagem e espetáculo no discurso pós-moderno. Rio de Janeiro: Revista LOGOS, 2009. Disponível em: https://www.epublicacoes.uerj.br/index.php/logos/article/view/361. Acesso em: 23 mar. 2019.

SABBAGA, Julia. The Umbrella Academy | Jogadora Marta entra para família em comercial. 20 de fev.2019. Disponível: https://www.omelete.com.br/series-tv/the-umbrella-academy-jogadora-marta-entrapara-familia-em-comercial. Acesso em: 28 abr. 2019.

SCHIFFMAN, Leon G. KANUK, Leslie Lazar. Comportamento do consumidor. Rio de Janeiro: LTC - Livros Técnicos e Científicos Editora S.A., 2000.

SERY. Ilustração do personagem Seis da série The Umbrella Academy. Depok, 19 de fev. 2019. Instagram: @ghostdog.s. Disponível em: https://www.instagram.com/p/BuFHK39HgEN/. Acesso em: 4 de mai. 2019.

SILVERSTONE, Roger. Por que estudar a Midia?. São Paulo: Edições Loyola Jesuítas, 1999.

STAR WARS. Meet the winners of the Star Wars fan awards 2018!. 12 de dez. 2019. Disponível em: https://www.starwars.com/news/meet-the-winners-of-the-star-wars-fan-awards-2018. Acesso em: 28 abr. 2019. 
THIEL, Cristiane Rocha. Leads: Mídia Própria, Paga e Espontânea. 2019. Disponível em: https://cristianethiel.com.br/leads-midia-propria-paga-e-espontanea/. Acesso em: 17 mar. 2019.

THE UMBRELLA ACADEMY. Instagram: @umbrellaacad. 2019. Disponível em: https://www.instagram.com/umbrellaacad/. Acesso em: 8 abr. 2019.

\section{THETHINGS. The Umbrella Academy The Biggest Differences Between The Netflix Show And The}

Comics. 2019. (6m42s). Disponível em: https://www.youtube.com/watch?v=DiduN9NFhms\&t. Acesso em: 4 maio 2019.

UMBRELLA ACADEMY. Twitter: @UmbrellaAcad. 2019. Disponível em: https://twitter.com/UmbrellaAcad. Acesso em: 8 abr. 2019.

UMBRELLA ACADEMY. Facebook: Umbrella Academy. 2019. Disponível em: https://www.facebook.com/NetflixUmbrellaAcademy/. Acesso em: 8 abr. 2019.

UNILEVER. Unilever Brasil. 2019. Página inicial. Disponível em: https://www.unilever.com.br/. Acesso em: 17 mar. 2019.

UOL. Nada de pausa: post misterioso de Marta não passa de ação da Netflix. São Paulo, 20 de fev. 2019. Disponível em: https://www.uol.com.br/esporte/futebol/ultimas-noticias/2019/02/20/nada-de-pausa-postmisterioso-de-marta-nao-passa-de-acao-da-netflix.htm. Acesso em: 28 abr. 2019.

VERONEZZI, José Carlos. Mídia de A a Z: conceitos, critérios e fórmulas dos 60 principais termos de mídia. São Paulo: Pearson Prentice Hall, 2009.

WHEELER, Alina. Design de identidade da marca. Porto Alegre: Bookman, 2012.

XAVIER, Adilson. Storytelling. 1. ed. Rio de Janeiro: BestSeller, 2015. 